\title{
Hemodynamic performance and outcome of percutaneous versus surgical stentless bioprostheses for aortic stenosis with anticipated patient-prosthesis mismatch
}

\author{
Arie Finkelstein, MD, ${ }^{\mathrm{a}}$ Arie Lorin Schwartz, MD, ${ }^{\mathrm{a}}$ Gideon Uretzky, MD, ${ }^{\mathrm{b}}$ Shmuel Banai, MD, ${ }^{\mathrm{a}}$ \\ Gad Keren, MD, ${ }^{\mathrm{a}}$ Amir Kramer, MD, ${ }^{\mathrm{b}}$ and Yan Topilsky, $\mathrm{MD}^{\mathrm{a}}$
}

\begin{abstract}
Objectives: We aimed to compare the performance and midterm survival of transcutaneous aortic valve replacement (TAVR) and surgically implanted stentless aortic valve replacement (SAVR) for severe aortic stenosis in patients anticipated to have patient-prosthesis mismatch (PPM).
\end{abstract}

\begin{abstract}
Methods: A retrospective analysis was performed of 86 and 49 consecutive TAVR and SAVR patients with severe aortic stenosis and calculated minimal effective orifice area larger than the best projected effective orifice area. Cox hazard analyses were used to assess the effect of TAVR versus SAVR on outcome.

Results: The peak and mean transprosthetic gradient at discharge were lower $(P<.001$ for both $)$ in the TAVR group. Mild or greater aortic regurgitation was more frequent in the TAVR group $(61 \%$ vs $7 \%$; $P<.0001)$. At 3 months of follow-up, the mean gradient in the TAVR group was similar to that of the SAVR group but the prevalence of aortic regurgitation was still higher. The unadjusted 3-year survival rate was superior in the SAVR versus TAVR group $(91.6 \% \pm 4 \%$ vs $67.0 \% \pm 7 \% ; P=.01)$. Adjustments for both age and comorbidity resulted in loss of the difference in mortality between the 2 groups.
\end{abstract}

Conclusions: In patients with anticipated PPM, TAVR offers an immediate lower incidence of PPM than SAVR but a greater prevalence of aortic regurgitation. The differences in transaortic gradients became nonsignificant 3 months postoperatively. The question of whether TAVR is a suitable substitute for SAVR in patients with anticipated PPM, in particular, those who are older and sicker, warrants additional investigation. (J Thorac Cardiovasc Surg 2014;147:1892-9)

Patient-prosthesis mismatch (PPM) occurs when the effective orifice area (EOA) of a normally functioning prosthesis is too small in relation to the patient's body size, resulting in an abnormally high postoperative gradient. ${ }^{1}$ Aortic valve replacement (AVR) in patients with a small aortic annulus for the body surface area (BSA) has been associated with a high incidence of PPM, ${ }^{2-4}$ which has been associated with increased mortality, more congestive heart failure, and worse functional capacity. ${ }^{5}$ The most widely validated parameter for identifying PPM is the calculated EOA, indexed by the patient's BSA $^{6}$ (iEOA). When the aortic iEOA is less than $0.85 \mathrm{~cm}^{2} / \mathrm{m}^{2}$, the patient is considered to have moderate PPM, and when the aortic iEOA is less than $0.65 \mathrm{~cm}^{2} / \mathrm{m}^{2}$, the patient has severe PPM. To avoid PPM, the minimal EOA of the

From the Divisions of Cardiovascular Diseases ${ }^{\mathrm{a}}$ and Cardiovascular Surgery, ${ }^{\mathrm{b}} \mathrm{Tel}$ Aviv Medical Center, Tel-Aviv, Israel.

Disclosures: Authors have nothing to disclose with regard to commercial support.

Drs Finkelstein and Schwartz contributed equally to this study.

Received for publication March 26, 2013; revisions received June 19, 2013; accepted for publication July 9, 2013; available ahead of print Aug 30, 2013.

Address for reprints: Yan Topilsky, MD, Division of Cardiovascular Disease,

Tel Aviv Medical Center, Sami Ofer Bldg, Weizmann 6 St, Tel-Aviv, Israel

(E-mail: topilskyyan@gmail.com).

0022-5223/\$36.00

Copyright (c) 2014 by The American Association for Thoracic Surgery

http://dx.doi.org/10.1016/j.jtcvs.2013.07.008 prosthesis to be inserted ${ }^{1}$ is calculated by multiplying the patient's BSA by 0.85 and compared with the projected EOA, defined by the size of the patient's annulus diameter and the manufacturer's reference value. Whenever the minimal EOA is more than the projected EOA, PPM is anticipated. For anticipated PPM, several solutions have been proposed, from which AVR with stentless valves (SAVR) has gained popularity owing to the excellent iEOA, low transprosthetic gradients, and greater left ventricular (LV) mass regression. ${ }^{7}$ Recently, transcatheter aortic valve replacement (TAVR) has emerged as an alternative to AVR for high-risk patients with aortic stenosis, ${ }^{8}$ with respect to relief of stenosis and postprocedural valve hemodynamics. ${ }^{9}$

We sought to compare the hemodynamics and early and midterm outcomes in patients with anticipated PPM, who were treated with either SAVR or TAVR, at our institution.

\footnotetext{
METHODS

Eligibility and Projected iEOA

Patients were eligible for analysis if they had severe aortic stenosis and were anticipated to have at least moderate PPM according to their BSA and annulus size, assuming a stented bioprosthesis were implanted. To define eligibility, we used the following strategy before aortic valve intervention. ${ }^{3}$ We calculated the patient's BSA; calculated the minimal required EOA by multiplying the BSA by $0.85 \mathrm{~cm}^{2} / \mathrm{m}^{2}$; and compared the result obtained in the second step with that of the projected EOA. ${ }^{10}$ Patients were eligible for
} 


\section{Abbreviations and Acronyms \\ $\mathrm{AR} \quad=$ aortic regurgitation \\ AVR $=$ aortic valve replacement \\ $\mathrm{BSA}=$ body surface area \\ $\mathrm{CI}=$ confidence interval \\ EOA $=$ effective orifice area \\ $\mathrm{iEOA}=$ calculated EOA, indexed by the patient's body surface area \\ $\mathrm{HR}=$ hazard ratio \\ $\mathrm{LV}=$ left ventricular \\ NYHA $=$ New York Heart Association \\ PPM = patient-prosthesis mismatch \\ SAVR $=$ stentless aortic valve replacement \\ TAVR $=$ transcatheter aortic valve replacement}

the present study if their minimal required EOA was larger than the highest projected EOA for any type of available stented bioprosthesis.

\section{SAVR Procedure}

All SAVR patients underwent AVR with a Freestyle stentless bioprosthesis (Medtronic Inc, Minneapolis, Minn). The operative technique has been previously described. ${ }^{11}$ In brief, all operations were performed through a standard midline sternotomy. Excision of the native aortic valve and annular debridement were followed by sizing with the sizer provided for the Freestyle stentless bioprosthesis valve, with consideration given to the size at both the annulus and the sinotubular ridge. The Freestyle valve was then inserted in the subcoronary position or as a full root replacement. When subcoronary insertion was applied, a 2-layer suture technique was used.

\section{TAVR Procedure}

All TAVR procedures were performed in patients with severe symptomatic aortic stenosis with a balloon-expandable valve (Edwards SAPIEN, Edwards LifeSciences, Inc, Irvine, Calif) or a self-expandable valve (CoreValve, Medtronic, Inc) through the transfemoral approach with the patient under local anesthesia. The valve prosthesis size was selected on the basis of the aortic annulus measurements obtained by transesophageal echocardiography performed before the procedure. For the balloonexpandable valve, a $23-\mathrm{mm}$ valve was selected if the aortic annulus was 17 to $21 \mathrm{~mm}$, with a 26-mm valve selected, if the aortic annulus was 22 to $25 \mathrm{~mm}$. For the self-expandable valve, a $26-\mathrm{mm}$ valve was selected if the aortic annulus was 20 to $23 \mathrm{~mm}$, with a $29-\mathrm{mm}$ valve selected if the aortic annulus was 23 to $27 \mathrm{~mm}$. Balloon aortic valvuloplasty was performed in all patients before valve implantation. Immediately after valve deployment, evaluation of the presence and severity of aortic regurgitation (AR) was assessed visually by determination of the relative amount of radiographic contrast medium in the ventricle after injection into the proximal aorta and classified using a scale of 0 to 4 . Balloon dilation was performed in cases of significant paravalvular AR, defined as AR of grade 2 or greater. After balloon dilation, the presence and degree of AR was again evaluated, and a second dilation was performed at the discretion of the physician.

\section{Study Design}

The present study was a nonrandomized, retrospective, single-center study. Because it was judged to be a low-risk, retrospective analysis, the institutional review board approved wavering of informed consent. The study was designed with 2 aims. First, to assess the hemodynamic performance of TAVR compared with SAVR in terms of the transprosthetic gradient and prevention of severe PPM in patients identified to have a high risk of PPM. Second, the TAVR and SAVR patients were compared for midterm survival.

The first step was to identify the TAVR cohort. From January 2009 to December 2011, 200 TAVR procedures were performed in patients with severe aortic stenosis at our institution. In 86 patients, the calculated minimal EOA was larger than the best projected EOA ${ }^{10}$ for any type of available stented bioprosthesis, and these patients were considered eligible for analysis (TAVR cohort). Second, we compared the TAVR patients with 49 consecutive patients (SAVR cohort) with severe aortic stenosis, identified from a prospective registry database of all 192 patients who had undergone SAVR with a stentless Freestyle bioprosthesis (Medtronic, Inc) during the same period, who were similar to the TAVR group for the predefined inclusion characteristics. The patients in both cohorts (TAVR and SAVR) had undergone AVR contemporaneously. The presence of a bicuspid aortic valve was a contraindication for TAVR, and we, therefore, also excluded patients with a bicuspid valve from the SAVR cohort. All echocardiographic data were collected at baseline, before hospital discharge, and at the 3-month follow-up examination. Survival was calculated from AVR (either TAVR or SAVR) until the date of the last clinical encounter for all patients.

\section{Baseline, Follow-up, and Clinical Outcomes}

The baseline clinical data were collected by interviewing the patients and reviewing their medical files. Coexisting conditions were evaluated using the Charlson comorbidity index, ${ }^{12}$ which contains different categories of comorbidities. Clinical follow-up data were obtained by a review of the medical records, surveys, and telephone interviews. The cause of death was determined by a review of all medical records, telephone interviews, and death certificates. The event used as the endpoint was all-cause mortality.

\section{Echocardiography}

Two-dimensional transthoracic echocardiography was performed in a standard manner using the same equipment (iE33, Philips Medical Systems, Bothell, Wash).

The ejection fraction was calculated using the Simpson method, ${ }^{13}$ and the LV diameters, interventricular septal and posterior wall width, LV mass, relative wall thickness, LV stroke, and cardiac output were calculated as recommended. ${ }^{13}$

The severity of aortic stenosis was defined by the maximal velocity across the aortic valve, the mean pressure gradient, and the aortic valve area, calculated by the standard continuity equation (maximal velocity, $>4 \mathrm{~m} / \mathrm{s}$; mean gradient, $>40 \mathrm{~mm} \mathrm{Hg}$; and aortic valve area, $<1.0 \mathrm{~cm}^{2}$ ). Grading of AR after TAVR or SAVR was performed in a semiquantitative fashion, using color Doppler imaging, according to the number of jets, the jet width in the central jets, and the circumferential extent of the jet in paravalvular AR using the parasternal long-axis, parasternal short-axis, and apical long-axis views. AR was classified as follows: 0 , absent; 1 , trivial or mild; 2 , mild-to-moderate; 3 , moderate; and 4 , severe. To estimate the effective regurgitant orifice (EOA) after TAVR, we used the methods described by Clavel et al. ${ }^{14}$

\section{Statistical Analysis}

Continuous normally distributed parameters are presented as the mean \pm standard deviation and were compared using the Student $t$ test or paired $t$ test, as appropriate. Ordinal and/or non-normally distributed data are presented as the median and first and third quartiles and were compared using the Wilcoxon rank sum or Wilcoxon signed rank test. Categorical data were compared between groups using the chi-square test or Fisher's exact test, whenever the expected values in any of the cells of a contingency table were less than 5. Unadjusted and adjusted Cox proportional hazards 
were used to analyze the association of the use of TAVR versus SAVR, with calculation of the hazard ratios (HRs) and 95\% confidence intervals (CIs). Event distributions were calculated using the Kaplan-Meier method and compared using the log-rank test. All $P$ values were 2 -sided, and $P<.05$ were considered statistically significance. All data were analyzed using the JMP system software, version 9.0 (SAS Institute, Inc, Cary, NC), and Statistical Package for Social Sciences, version 17.0, software package (SPSS Inc, Chicago, Ill)

\section{RESULTS}

\section{Baseline Characteristics}

The baseline characteristics of the enrolled patients $(\mathrm{n}=135)$ stratified by use of TAVI or SAVR are listed in Table 1. The mean age of entire cohort was $79.0 \pm 7$ years, and $33 \%$ were men. The cause of AS was degenerativecalcific in all patients, and all patients were symptomatic (New York Heart Association [NYHA] class II or greater). The median and first and third quartiles for logistic EuroSCORE II was 5.6 and 3.7 and 9.0 and for the Charlson comorbidity index was 5.9 and 4.9 and 6.8. Previous coronary bypass had been performed in 3 patients $(6 \%)$ in the SAVR group and $14(16 \%)$ in the TAVR group $(P=.2)$. None of the procedures in either group was performed emergently or because of a critical state, and none of the patients in either group needed an intra-aortic balloon pump before the procedure. The baseline echocardiographic data for the entire study population showed the following mean values: left ventricular ejection fraction, $56.2 \% \pm 7 \%$; aortic peak pressure gradient, $77.7 \pm 25 \mathrm{~mm} \mathrm{Hg}$; aortic mean pressure gradient, $46.3 \pm 16 \mathrm{~mm} \mathrm{Hg}$; and aortic valve area, $0.66 \pm 0.16 \mathrm{~cm}^{2}$.

A comparison between groups verified that the BSA, gender, LV outflow tract diameter, and peak and mean pressure gradients were similar. Additional echocardiographic Doppler parameters, such as ejection fraction, diastolic parameters, and right ventricular systolic pressure, displayed no difference between the 2 groups (Table 1). The TAVR patients were older, with a greater NYHA functional class and higher logistic EuroSCORE II and Charlson comorbidity scores.

\section{Operative Outcomes and Operative Mortality}

The postprocedural outcomes for all patients stratified by procedure are listed in Table 2. The valve types and sizes in the TAVR group were Edwards SAPIEN (Edwards LifeSciences) $23 \mathrm{~mm}$ in 6 patients and $26 \mathrm{~mm}$ in 3 patients, CoreValve $26 \mathrm{~mm}$ (Medtronic, Inc) in 45 patients and 29 $\mathrm{mm}$ in 32 patients. The valve sizes in the SAVR group were $21 \mathrm{~mm}$ in 6 patients, $23 \mathrm{~mm}$ in 14 patients, $25 \mathrm{~mm}$ in 17 patients, $27 \mathrm{~mm}$ in 8 patients, and $29 \mathrm{~mm}$ in 4 patients. Aortic root enlargement and Bentall procedures were not used in the SAVR patients. In patients with SAVR, the cardiopulmonary bypass time was $122.9 \pm 45.5$ minutes, and the aortic crossclamp time was $96.7 \pm 36.8$ minutes. In 46 of the SAVR patients (94\%), implantations were subcoronary, and in $3(6 \%)$, concomitant aortic surgery on the thoracic aorta was performed. The rate of intervention for associated coronary artery disease, specifically concomitant coronary bypass and SAVR versus adjuvant percutaneous coronary intervention before TAVR was not different (23 [47\%] vs $47[55 \%]$, respectively; $P=.4)$. The median duration of the length of stay was 7 days (6 vs 9 days, respectively; $P=.3$ ) and was not different between the 2 groups. Of the 135 patients, 4 died before discharge, $3(3 \%)$ in the TAVR group and $1(2 \%)$ in the SAVR group $(P=.6)$. All the patients who died in hospital died during the 30-day period after surgery, but none died during the AVR surgery. The cause of early postoperative mortality was acute left heart failure with cardiogenic shock in 1 patient and sepsis in 2 patients in the TAVR group and multiorgan failure in the SAVR patient. The only difference between the groups in terms of early complications was a greater rate of need for a new pacemaker in the TAVR group $(16 \%$ vs $2 \% ; P=.01)$.

\section{Doppler Echocardiographic Data}

The Doppler echocardiographic data at hospital discharge are listed in Table 2. The peak and mean transprosthetic gradient were lower $(P<.0001$ for both) at discharge in the TAVR group than in the SAVR group and the aortic valve area, aortic valve area index, and dimensionless left ventricular to transprosthetic velocity integral ratio were larger $(P<.0001$ for all $)$. The incidence of PPM before discharge was greater $(P=.002)$ in the SAVR group (30\%) than in the TAVR group $(6 \%)$. At least mild AR was present in $61 \%$ of the TAVR patients compared with $7 \%$ of the SAVR patients, immediately after the procedure $(P<.0001)$. AR was paravalvular in all the cases in the TAVR group. The Doppler echocardiographic data at 3 months of follow-up are listed in Table 2. No significant changes were found in the mean transvalvular gradient, aortic valve area, or aortic valve area index between hospital discharge and 3 months of follow-up in the TAVR patients $(P>.4$ for all variables). In contrast, the peak transvalvular gradient $(P=.04)$ and mean transvalvular gradient $(P=.05)$ exhibited a significant reduction and the aortic valve area had increased $(P=.04)$ in the SAVR patients compared with at discharge. At 3 months of follow-up, no significant differences were observed regarding all the hemodynamic variables between the TAVR and SAVR groups $(P>.1$ for all variables). The incidence and degree of AR remained similar to those at hospital discharge in both groups, with a greater incidence of mild AR or greater in the TAVI group $(56 \%)$ than in the SAVR group $(0 \%)$.

\section{All-Cause Mortality}

The follow-up period was significantly longer in the SAVR group than in the TAVR group $(3.6 \pm 1.7$ years 
TABLE 1. Baseline and echocardiographic characteristics of patients with severe aortic stenosis and anticipated PPM overall and stratified by TAVR or SAVR

\begin{tabular}{|c|c|c|c|}
\hline Variable & $\begin{array}{c}\text { TAVR } \\
(\mathbf{n}=\mathbf{8 6})\end{array}$ & $\begin{array}{c}\text { SAVR } \\
(n=49)\end{array}$ & $\begin{array}{c}P \\
\text { value }\end{array}$ \\
\hline \multicolumn{4}{|l|}{ Demographic parameters } \\
\hline Weight $(\mathrm{kg})$ & $75.6 \pm 14.5$ & $79.9 \pm 15.2$ & .1 \\
\hline Height $(\mathrm{cm})$ & $163.0 \pm 8.2$ & $166.2 \pm 10.4$ & .07 \\
\hline BMI $\left(\mathrm{kg} / \mathrm{m}^{2}\right)$ & $28.4 \pm 4.9$ & $28.9 \pm 5.2$ & .6 \\
\hline $\operatorname{BSA}\left(\mathrm{m}^{2}\right)$ & $1.81 \pm 0.18$ & $1.86 \pm 0.20$ & .2 \\
\hline Age (y) & $82.4 \pm 5.05$ & $73.0 \pm 7.77$ & $<.001$ \\
\hline Male gender (n) & $28(32)$ & $16(32)$ & .9 \\
\hline \multicolumn{4}{|l|}{ Echocardiographic parameters } \\
\hline $\mathrm{EF}(\%)$ & $56.8 \pm 6.5$ & $55.0 \pm 7.9$ & .2 \\
\hline IVSd (cm) & $1.3 \pm 0.2$ & $1.4 \pm 0.3$ & .3 \\
\hline LVEDD (cm) & $4.4 \pm 0.7$ & $4.7 \pm 0.7$ & .02 \\
\hline PWd (cm) & $1.2(1,1.3)$ & $1.2(1.1,1.3)$ & .5 \\
\hline LV mass $(\mathrm{g})$ & $219.7 \pm 65$ & $252.5 \pm 83$ & .02 \\
\hline RWT & $1.05 \pm 0.4$ & $0.93 \pm 0.3$ & .05 \\
\hline LVESD $(\mathrm{cm})$ & $2.7 \pm 0.7$ & $3.0 \pm 0.7$ & .01 \\
\hline LVOT diameter $(\mathrm{cm})$ & $1.95 \pm 0.11$ & $1.94 \pm 0.13$ & .7 \\
\hline Stroke volume $(\mathrm{mL})$ & $64(57,75)$ & $68(49,84)$ & .5 \\
\hline E wave $(\mathrm{cm} / \mathrm{s})$ & $108.4 \pm 38.3$ & $97.0 \pm 32.3$ & .09 \\
\hline E deceleration time (ms) & $254(172,328)$ & $203(180,254)$ & .4 \\
\hline A wave $(\mathrm{cm} / \mathrm{s})$ & $106.7 \pm 30.01$ & $95.6 \pm 30.3$ & .07 \\
\hline Transaortic Vmax $(\mathrm{cm} / \mathrm{s})$ & $439.8 \pm 57.3$ & $416.4 \pm 89.2$ & .1 \\
\hline $\begin{array}{l}\text { Peak pressure transaortic } \\
\text { gradient }(\mathrm{mm} \mathrm{Hg})\end{array}$ & $78.8 \pm 21.3$ & $75.5 \pm 31.6$ & .5 \\
\hline $\begin{array}{l}\text { Mean pressure transaortic } \\
\text { gradient }(\mathrm{mm} \mathrm{Hg})\end{array}$ & $47.9 \pm 13.7$ & $43.1 \pm 19.2$ & .2 \\
\hline $\operatorname{AVA}\left(\mathrm{cm}^{2}\right)$ & $0.64 \pm 0.15$ & $0.71 \pm 0.17$ & .2 \\
\hline RA pressure (mm Hg) & $5(5,10)$ & $5(5,5)$ & .01 \\
\hline $\begin{array}{l}\text { Systolic pulmonary pressure } \\
(\mathrm{mm} \mathrm{Hg})\end{array}$ & $40.8 \pm 16.4$ & $37.1 \pm 12.2$ & .2 \\
\hline Mitral regurgitation & & & .1 \\
\hline None & $24(28)$ & $16(33)$ & \\
\hline Mild & $55(64)$ & $30(61)$ & \\
\hline Moderate & $6(7)$ & $3(6)$ & \\
\hline Severe & $1(1)$ & $0(0)$ & \\
\hline AR & & & .05 \\
\hline None & $34(39)$ & $22(45)$ & \\
\hline Mild & $49(57)$ & $22(45)$ & \\
\hline Moderate & $3(4)$ & $3(6)$ & \\
\hline Severe & $0(0)$ & $2(4)$ & \\
\hline \multicolumn{4}{|l|}{ Clinical parameters } \\
\hline Preoperative critical state (n) & 0 & 0 & NS \\
\hline Recent MI (n) & 0 & 0 & NS \\
\hline Emergency surgery (n) & 0 & 0 & NS \\
\hline $\begin{array}{l}\text { Concomitant coronary } \\
\text { intervention }(\mathrm{n})\end{array}$ & $47(55)$ & $23(47)$ & .4 \\
\hline Surgery on thoracic aorta (n) & 0 & $3(6)$ & .05 \\
\hline Bicuspid aortic valve (n) & 0 & 0 & NS \\
\hline NYHA class $(\%)$ & & & .01 \\
\hline I & 0 & 0 & \\
\hline II & 0 & 8 & \\
\hline III & 75 & 65 & \\
\hline IV & 25 & 27 & \\
\hline
\end{tabular}

TABLE 1. Continued

\begin{tabular}{lclc}
\hline \multicolumn{1}{c}{ Variable } & $\begin{array}{c}\text { TAVR } \\
(\mathbf{n = 8 6 )}\end{array}$ & $\begin{array}{c}\text { SAVR } \\
(\mathbf{n = 4 9 )}\end{array}$ & $\begin{array}{c}\boldsymbol{P} \\
\text { value }\end{array}$ \\
\hline Atrial fibrillation (n) & $15(17)$ & $8(16)$ & .9 \\
Previous stroke (n) & $7(8)$ & $2(4)$ & .5 \\
Previous CABG (n) & $14(16)$ & $3(6)$ & .1 \\
Creatinine (mg/dL) & $1.19 \pm 0.67$ & $1.16 \pm 0.29$ & .7 \\
PVD (n) & $13(15)$ & $3(6)$ & .2 \\
CVA (n) & $6(7)$ & $4(8)$ & 1.0 \\
COPD (n) & $22(25)$ & $26(53)$ & .002 \\
Diabetes (n) & $25(29)$ & $16(33)$ & .7 \\
Solid tumor (n) & $9(10)$ & $1(2)$ & .09 \\
Logistic EuroSCORE II & $6.5(4.3,10.5)$ & $4.6(3.1,7.3)$ & .003 \\
Charlson score & $6.3(5.3,7.3)$ & $5.3(4.5,6.3)$ & .0009 \\
\hline
\end{tabular}

Data presented as mean \pm standard deviation, $\mathrm{n}(\%)$, or median (first, third quartile). $P P M$, Patient-prosthesis mismatch; TAVR, transcutaneous aortic valve replacement; $S A V R$, stentless surgical aortic valve replacement; $B M I$, body mass index; $B S A$, body surface area; $E F$, ejection fraction; IVSd, interventricular septum diameter; $L V E D D$, left ventricular end-diastolic diameter; $P W d$, posterior wall diameter; $N S$, not significant; $L V$, left ventricular; $R W T$, relative wall thickness; $L V E S D$, left ventricular end-systolic diameter; $L V O T$, left ventricular outflow tract; Vmax, maximal velocity; $A V A$, aortic valve area; $R A$, right atrium; $A R$, aortic regurgitation; $M I$, myocardial infarction; NYHA, New York Heart Association; $C A B G$, coronary artery bypass grafting; $P V D$, peripheral vascular disease; $C V A$, cerebrovascular accident; $C O P D$, chronic obstructive pulmonary disease.

vs $1.6 \pm 0.7$ years; $P<.0001)$. Of the 135 patients, 22 died. The unadjusted 3-year survival rate was lower in the TAVR group than in the SAVR group $(67.0 \% \pm 7.7 \%$ vs $91.6 \% \pm 4.0 \% ; P=.01)$. Cox proportional hazard analysis for parameters associated with all-cause mortality showed that the use of TAVR compared with SAVR was associated with increased mortality (HR, 3.5; 95\% CI, 1.3-11.0 for TAVR; $P=.01$; Figure 1 ). The clinical parameters significantly associated with increased mortality were age (HR, 1.02; 95\% CI, 1.02-1.17 for each year; $P=.005$ ) and a higher Charlson comorbidity index (HR, 1.46; 95\% CI, 1.08-2.0 for each grade; $P=.01$ ). Trends were seen for increased mortality with NYHA class greater than II before the procedure (HR, 1.9; 95\% CI, 0.8-4.8; $P=.1$ ), chronic obstructive pulmonary disease (HR, $2.5 ; 95 \% \mathrm{CI}$, 0.94-5.9; $P=.06$ ). The logistic EuroSCORE II, previous coronary artery bypass grafting, renal disease, diabetes, valve size, and BSA did not affect the overall mortality rates $(P>.3$ for all). The preprocedural echocardiographic parameters associated with increased mortality were lower peak and mean transprosthesis gradients (HR, 0.98 and $0.97 ; 95 \% \mathrm{CI}, 0.96$ and $0.94-0.99$ for an increase in gradient by $1 \mathrm{~mm} \mathrm{Hg}$, respectively; $P=.02$ for both]). Neither the aortic valve area, diastolic parameters, qualitatively estimated mitral regurgitation, nor tricuspid regurgitation peak velocity were associated with midterm mortality $(P>.3$ for all).

Table 3 and Figure 1 show the results of adjusted Cox proportional hazard analyses for all-cause mortality in all patients. Because of the small sample size and the low number of events, we restricted the explanatory variables 
TABLE 2. Clinical and echocardiographic postintervention outcomes after TAVR versus SAVR

\begin{tabular}{|c|c|c|c|}
\hline Variable & $\begin{array}{c}\text { TAVR } \\
(\mathbf{n}=\mathbf{8 6})\end{array}$ & $\begin{array}{c}\text { SAVR } \\
(n=49)\end{array}$ & $\begin{array}{c}P \\
\text { value }\end{array}$ \\
\hline \multicolumn{4}{|l|}{ Surgical outcome } \\
\hline Valve size $(\mathrm{mm})$ & $25(23,26.5)$ & $26(26,29)$ & $<.001$ \\
\hline Bypass time (min) & None & $122.9 \pm 45.5$ & NA \\
\hline Aortic crossclamp time (min) & None & $96.7 \pm 36.8$ & NA \\
\hline $\begin{array}{l}\text { Concomitant coronary } \\
\text { intervention }(\mathrm{n})\end{array}$ & $47(55)$ & $23(47)$ & .4 \\
\hline Length of stay (d) & $7(5,9)$ & $7(6,10)$ & .4 \\
\hline Early mortality (30 d) & $3(3.5)$ & $1(2.0)$ & .6 \\
\hline Need for new pacemaker (n) & $14(16)$ & $1(2)$ & .01 \\
\hline CVA (n) & $2(2)$ & $1(2)$ & 1.0 \\
\hline Tamponade (n) & $2(2)$ & $1(2)$ & 1.0 \\
\hline After MI (n) & 0 & 0 & 1.0 \\
\hline Acute renal failure (n) & $3(3)$ & $4(8)$ & .2 \\
\hline Infection (n) & $10(11)$ & $3(6)$ & .4 \\
\hline \multicolumn{4}{|l|}{$\begin{array}{l}\text { Echocardiographic parameters } \\
\text { before discharge }\end{array}$} \\
\hline Peak pressure gradient (mm Hg) & $16.3 \pm 6.7$ & $23.8 \pm 9.09$ & $<.001$ \\
\hline Mean pressure gradient $(\mathrm{mm} \mathrm{Hg})$ & $9.08 \pm 3.62$ & $12.5 \pm 4.83$ & .0002 \\
\hline AV Vmax $(\mathrm{cm} / \mathrm{s})$ & $195.6 \pm 38.8$ & $245.8 \pm 70.1$ & $<.001$ \\
\hline LVOT Vmax $(\mathrm{cm} / \mathrm{s})$ & $122.5 \pm 36.5$ & $114.7 \pm 23.6$ & .2 \\
\hline LVOT VTI (cm) & $23.52 \pm 6.43$ & $21.68 \pm 7.65$ & .2 \\
\hline Dimensionless index & $0.63 \pm 0.18$ & $0.49 \pm 0.14$ & .0001 \\
\hline AVA $\left(\mathrm{cm}^{2}\right)$ & $1.88 \pm 0.44$ & $1.43 \pm 0.41$ & $<.0001$ \\
\hline AVA index $\left(\mathrm{cm}^{2} / \mathrm{m}^{2}\right)$ & $1.05 \pm 0.25$ & $0.78 \pm 0.24$ & $<.0001$ \\
\hline Moderate PPM (n) & $15(17)$ & $31(74)$ & $<.0001$ \\
\hline Severe PPM (n) & $5(6)$ & $13(30)$ & .001 \\
\hline $\operatorname{AR}(\%)$ & & & $<.0001$ \\
\hline None & 39 & 93 & \\
\hline Mild & 61 & 7 & \\
\hline Moderate & 0 & 0 & \\
\hline Severe & 0 & 0 & \\
\hline \multicolumn{4}{|l|}{$\begin{array}{l}\text { 90-d Postprocedural } \\
\text { echocardiographic parameters }\end{array}$} \\
\hline Peak pressure gradient (mm Hg) & $14.9 \pm 6.6$ & $19.2 \pm 8.2$ & .2 \\
\hline Mean pressure gradient $(\mathrm{mm} \mathrm{Hg})$ & $8.4 \pm 3.9$ & $9.0 \pm 4.24$ & .7 \\
\hline AV Vmax $(\mathrm{cm} / \mathrm{s})$ & $190.2 \pm 42.4$ & $234.1 \pm 67.2$ & .1 \\
\hline LVOT Vmax $(\mathrm{cm} / \mathrm{s})$ & $116.2 \pm 27.9$ & $103.4 \pm 30.3$ & .4 \\
\hline LVOT VTI $(\mathrm{cm})$ & $23.1 \pm 5.6$ & $37.1 \pm 37.4$ & .4 \\
\hline Dimensionless index & $0.63 \pm 0.17$ & $0.51 \pm 0.22$ & .1 \\
\hline $\operatorname{AVA}\left(\mathrm{cm}^{2}\right)$ & $1.88 \pm 0.46$ & $1.71 \pm 0.81$ & .7 \\
\hline AVA index $\left(\mathrm{cm}^{2} / \mathrm{m}^{2}\right)$ & $1.05 \pm 0.27$ & $0.91 \pm 0.42$ & .5 \\
\hline Moderate PPM (n) & $17(19)$ & $8(16)$ & .8 \\
\hline Severe PPM (n) & $4(5)$ & $4(8)$ & .5 \\
\hline AR $(\%)$ & & & $<.0001$ \\
\hline None & 44 & 100 & \\
\hline Mild & 54 & 0 & \\
\hline Moderate & 1 & 0 & \\
\hline Severe & 1 & 0 & \\
\hline
\end{tabular}

Data presented as median (first, third quartile), mean \pm standard deviation, $\mathrm{n}(\%)$, or $\%$. AV, Aortic valve; $V T I$, velocity time integral; $P P M$, patient-prosthesis mismatch; $T A V R$, transcutaneous aortic valve replacement; $S A V R$, stentless surgical aortic valve replacement; $L V O T$, left ventricular outflow tract; $A V A$, aortic valve area; $A R$, aortic regurgitation; $M I$, myocardial infarction; $C V A$, cerebrovascular accident; $N A$, not applicable to 2 to 3 for each model. The adjusted Cox proportional hazard analysis for any echocardiographic parameter did not affect the association between higher mortality and TAVR $(P>.4$ for all). However, the adjustments for age or comorbidity weakened the association between TAVR and increased mortality (Figure 1), and the adjustment for both age and comorbidity resulted in survival similar to that of TAVR (Figure 1), although with a continued trend favoring SAVR.

\section{DISCUSSION}

Our results have shown that in patients identified as having a high risk of developing PPM, TAVR is associated with a lower immediate incidence of PPM but greater incidence of AR compared with SAVR. At 3 months of follow-up, the hemodynamic differences become nonsignificant. The early superior transprosthetic gradients obtained with TAVR did not translate into better survival. The SAVR patients had superior longterm survival in the nonadjusted analysis, that was partially corrected by adjustment for both age and comorbidities.

\section{PPM in TAVR Versus SAVR}

Numerous studies have recognized the significance of achieving optimal hemodynamic result after AVR. ${ }^{2}$ The present study is the first to evaluate the incidence of PPM and compare survival after TAVR versus SAVR in a selected group of patients with anticipated PPM. We found a low early incidence of severe PPM (5\%) with TAVR, consistent with a previous report, ${ }^{15}$ that was lower than that with the use of the stentless valve, as previously described. ${ }^{9,16}$ The hemodynamic performance of the stentless bioprostheses continued to improve in the 3 months after surgery, converting the significant early difference in the incidence of PPM between SAVR and TAVR to an insignificant trend after 3 months. These results are in accordance with reports by other groups, ${ }^{17,18}$ showing comparable rates of severe PPM among patients with a small aortic root undergoing SAVR or TAVR.

The possible reasons for the early superior performance of TAVR compared with the stentless valve might be that valve sizing during SAVR is limited by the dimensions of the aortic annulus. In contrast, TAVR is systematically performed with an oversized valve, leading to some distension of the aortic annulus to accommodate the valve. In addition, the unique design of the TAVR prosthesis provides minimal obstruction to blood flow. ${ }^{9}$ In summary, our findings suggest that in selected patients anticipated to have PPM, compared with SAVR, TAVR provides better immediate results, which become comparable after 3 months.

\section{Midterm Mortality and Outcomes}

In patients with anticipated PPM, the procedural risk of SAVR and TAVR is reasonable. The significant decline in 


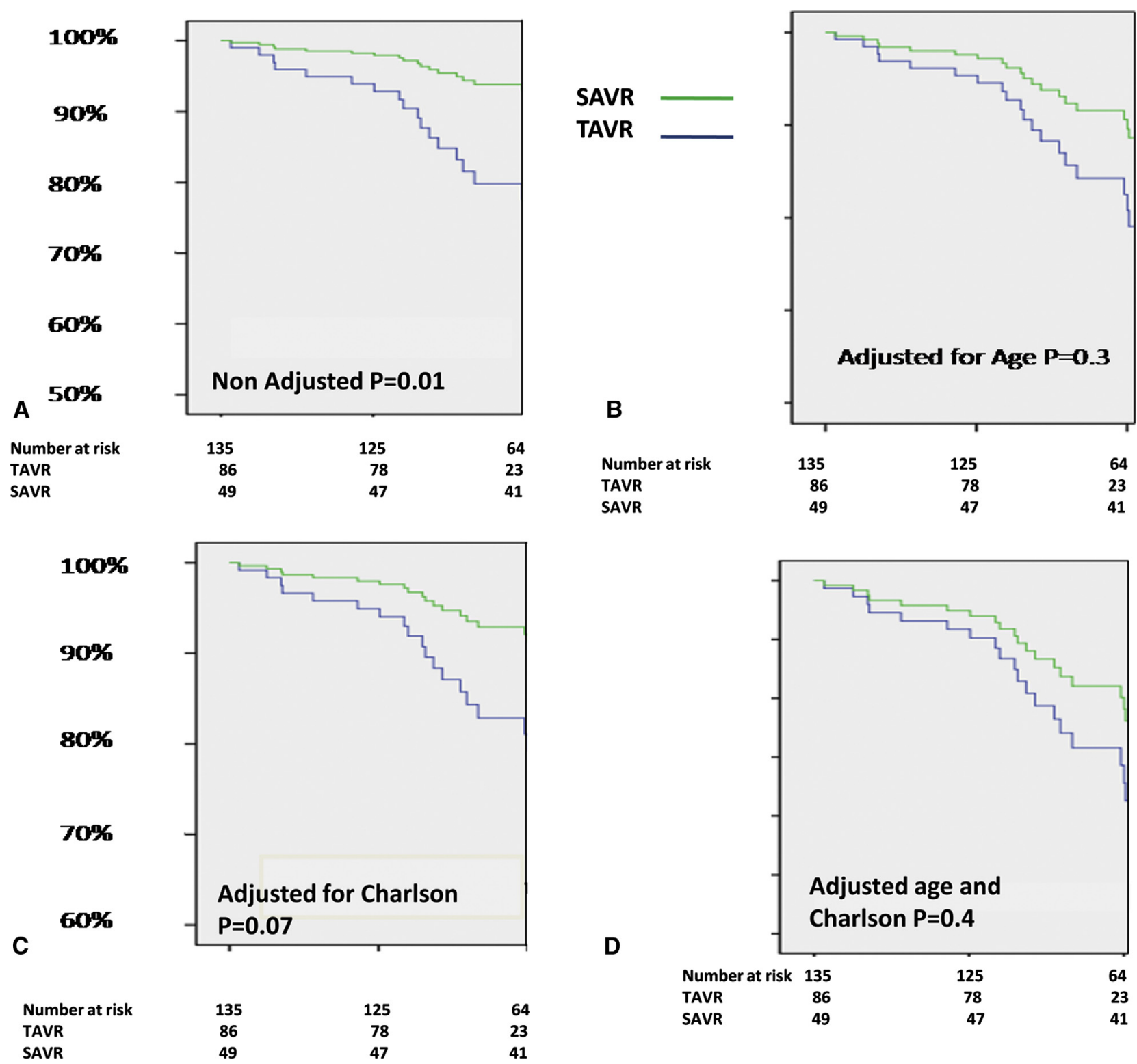

FIGURE 1. Adjusted Cox hazard survival plots stratified by transcutaneous aortic valve replacement (TAVR) versus stentless aortic valve replacement $(S A V R)$. A, Plot showing that unadjusted survival was significantly better with SAVR. B and C, Plots showing that the differences in survival became nonsignificant when adjusting for age or Charlson comorbidity index, respectively. Note, a trend was seen for improved survival with SAVR when adjusting for either age or comorbidity index alone. D, Adjustment for both age and comorbidity showed similar survival in both SAVR and TAVR.

midterm survival in patients with a low stroke volume and low transaortic gradient and the trend for increased mortality in patients with NYHA class greater than II might suggest that we should intervene at an earlier stage before patients have developed severe cardiac dysfunction and are only mildly symptomatic.

Survival was better with SAVR than with TAVR, in discordance with the superior early transaortic gradients of TAVR and lower incidence of early PPM. The increased mortality observed in the TAVR patients could possibly be explained by the combination of several factors. First, and most important, the TAVR patients were older and more ill, adversely affecting their midterm survival. Importantly, when adjusting or matching for the differences in both age and comorbidities between the groups, the survival was similar, as described in previous reports. ${ }^{19}$ However, the trend for improved survival in SAVR was not entirely corrected by matching for typical risk factors. Thus, we believe that TAVR can be considered as a possible solution in older patients with significant comorbidities and anticipated PPM but should not be used as the first line of therapy in patients with a low risk of surgical AVR. Second, 
TABLE 3. Adjusted analysis with Cox proportional hazards models of midterm mortality

\begin{tabular}{|c|c|c|c|c|c|}
\hline Variable & $\begin{array}{c}\text { TAVR versus SAVR, } \\
\text { nonadjusted }\end{array}$ & Peak aortic pressure & Age & Charlson index & Charlson index and age \\
\hline TAVR vs SAVR & $3.5\left(1.3-11.0 ; .01^{*}\right)$ & $4.5\left(1.6-15.3 ; .003^{*}\right)$ & $1.9(0.6-7.2 ; .3)$ & $2.5(0.95-8.1 ; .07)$ & $1.6(0.5-5.9 ; .4)$ \\
\hline Age (y) & - & - & $1.06\left(1.0-1.16 ; .05^{*}\right)$ & - & $1.09\left(1.01-1.19 ; .03^{*}\right)$ \\
\hline Male gender & - & - & - & - & - \\
\hline Charlson comorbidity index & - & - & - & $1.4(1.02-1.9 ; .03 *)$ & $1.4\left(1.01-1.8 ; .05^{*}\right)$ \\
\hline $\mathrm{EF}(\%)$ & - & - & - & - & - \\
\hline End systolic diameter $(\mathrm{cm})$ & - & - & - & - & - \\
\hline $\begin{array}{l}\text { Peak aortic systolic pressure } \\
(\mathrm{mm} \mathrm{Hg})\end{array}$ & - & $0.97(0.95-0.99 ; .005 *)$ & - & - & - \\
\hline $\begin{array}{l}\text { Mild or greater AR after } \\
\text { procedure }\end{array}$ & - & - & - & - & - \\
\hline
\end{tabular}

fraction; $A R$, aortic regurgitation. *Statistically significant.

most of the patients in our TAVR cohort had at least mild AR after the procedure, which has been shown to adversely affect the midterm outcome. ${ }^{20}$ The greater prevalence of AR after TAVR could offset the beneficial effect on survival of less PPM. Third, although PPM has been shown to adversely affect survival, there is likely a complex interplay between different patient-related factors and their effect on outcome. PPM decreases survival mainly in younger patients ${ }^{21}$ and in patients with a poor ejection fraction, ${ }^{21}$ pre-existing left ventricular dysfunction, ${ }^{22}$ and severe concentric hypertrophy, ${ }^{23}$ all of which were underrepresented in our cohort, which might have "diluted" the positive effect of lesser early PPM in the TAVR group on the overall outcome.

\section{Study Limitations}

The study cohort was small, and the differences in age and comorbid conditions were large between the TAVR and SAVR groups. Because of the relatively small number of patients, follow-up of less than 3 years for most TAVR patients, and the small number of events, we lacked the statistical power to predict the long-term outcomes, and some potentially important associations (NYHA, logistic EuroSCORE II) did not reach significance. Although SAVR offers good hemodynamic outcomes, it has never demonstrated superior outcomes compared with the routine stented valves. Our local routine has been to perform SAVR in all patients with expected PPM whenever surgical AVR was planned; thus, we were unable to analyze whether TAVR performs better or worse than SAVR in patients with expected PPM. Furthermore, the aortic crossclamp time was prolonged compared with the Society of Thoracic Surgeons mean crossclamp time, possibly owing to the complexity of SAVR, which might have biased our results in favor of TAVR.

\section{CONCLUSIONS}

In patients with anticipated PPM, TAVR offers immediate lower transaortic gradients than SAVR but a greater prevalence of AR. The differences in the transaortic gradients became nonsignificant 3 months after surgery. Nonadjusted survival was superior in the SAVR group but comparable when adjusted for both age and comorbidity. The question of whether TAVR is a suitable substitute for SAVR in patients with anticipated PPM, in particular, those who are older and sicker, warrants additional investigation.

\section{References}

1. Pibarot P, Dumesnil JG. Hemodynamic and clinical impact of prosthesis-patient mismatch in the aortic valve position and its prevention. J Am Coll Cardiol. 2000; 36:1131-41.

2. Rahimtoola SH. The problem of valve prosthesis-patient mismatch. Circulation. 1978;58:20-4.

3. Pibarot P, Dumesnil JG. Prosthesis-patient mismatch: definition, clinical impact, and prevention. Heart. 2006;92:1022-9.

4. Bleiziffer S, Eichinger WB, Hettich I, Ruzicka D, Wottke M, Bauernschmitt R, et al. Impact of patient-prosthesis mismatch on exercise capacity in patients after bioprosthetic aortic valve replacement. Heart. 2008;94:637-41.

5. Dumesnil JG, Honos GN, Lemieux M, Beauchemin J. Validation and applications of indexed aortic prosthetic valve areas calculated by Doppler echocardiography. J Am Coll Cardiol. 1990;16:637-43.

6. Kunadian B, Vijayalakshmi K, Thornley AR, de Belder MA, Hunter S, Kendall S, et al. Meta-analysis of valve hemodynamics and left ventricular mass regression for stentless versus stented aortic valves. Ann Thorac Surg. 2007;84:73-8.

7. Leon MB, Smith CR, Mack M, Miller DC, Moses JW, Svensson LG, et al. Transcatheter aortic-valve implantation for aortic stenosis in patients who cannot undergo surgery. N Engl J Med. 2010;363:1597-607.

8. Clavel MA, Webb JG, Pibarot P, Altwegg L, Dumont E, Thompson C, et al. Comparison of the hemodynamic performance of percutaneous and surgical bioprostheses for the treatment of severe aortic stenosis. J Am Coll Cardiol. 2009;53:1883-91.

9. Dumesnil JG, Pibarot P. Prosthesis-patient mismatch: an update. Curr Cardiol Rep. 2011;13:250-7.

10. Doty DB, Cafferty A, Kon ND, Huysmans HA, Krause AH Jr, Westaby S. Medtronic Freestyle aortic root bioprosthesis: implant techniques. J Card Surg. 1998; 13:369-75.

11. Charlson M, Szatrowski TP, Peterson J, Gold J. Validation of a combined comorbidity index. J Clin Epidemiol. 1994;47:1245-51.

12. Lang RM, Bierig M, Devereux RB, Flachskampf FA, Foster E, Pellikka PA, et al. Recommendations for chamber quantification: a report from the American Society of Echocardiography's Guidelines and Standards Committee and the Chamber Quantification Writing Group, developed in conjunction with the European Association of Echocardiography, a branch of the European Society of Cardiology. J Am Soc Echocardiogr. 2005;18:1440-63.

13. Clavel MA, Rodes-Cabau J, Dumont E, Bagur R, Bergeron S, De Larochelliere $\mathrm{R}$, et al. Validation and characterization of transcatheter aortic 
valve effective orifice area measured by Doppler echocardiography. JACC Cardiovasc Imaging. 2011;4:1053-62.

14. Hong S, Yi G, Youn YN, Lee S, Yoo KJ, Chang BC. Effect of the prosthesispatient mismatch on long-term clinical outcomes after isolated aortic valve replacement for aortic stenosis: a prospective observational study. J Thorac Cardiovasc Surg. Epub 2012 Sep 6.

15. Kukucka M, Pasic M, Dreysse S, Mladenow A, Habazettl H, Hetzer R, et al. Patient-prosthesis mismatch after transapical aortic valve implantation: incidence and impact on survival. J Thorac Cardiovasc Surg. 2013;145:391-7.

16. Pibarot P, Dumesnil JG, Jobin J, Cartier P, Honos G, Durand LG. Hemodynamic and physical performance during maximal exercise in patients with an aortic bioprosthetic valve: comparison of stentless versus stented bioprostheses. J Am Coll Cardiol. 1999;34:1609-17.

17. Cohen G, Christakis GT, Buth KJ, Joyner CD, Morgan CD, Sever JY, et al. Early experience with stentless versus stented valves. Circulation. 1997;96:II-76-82.

18. Cohen G, Christakis GT, Joyner CD, Morgan CD, Tamariz M, Hanayama N, et al. Are stentless valves hemodynamically superior to stented valves? A prospective randomized trial. Ann Thorac Surg. 2002;73:767-75; discussion 775-8.
19. Conradi L, Seiffert M, Treede H, Silaschi M, Baldus S, Schirmer J, et al Transcatheter aortic valve implantation versus surgical aortic valve replacement: a propensity score analysis in patients at high surgical risk. J Thorac Cardiovasc Surg. 2012;143:64-71.

20. Gilard M, Eltchaninoff H, Iung B, Donzeau-Gouge P, Chevreul K, Fajadet J, et al. Registry of transcatheter aortic-valve implantation in high-risk patients. $N$ Engl J Med. 2012;366:1705-15.

21. Girerd N, Mathieu P, Dumesnil JG, Magne J, Charbonneau E, Dagenais F, et al Impact of aortic stenosis severity and its interaction with prosthesis-patien mismatch on operative mortality following aortic valve replacement. $J$ Heart Valve Dis. 2012;21:158-67.

22. Ruel M, Al-Faleh H, Kulik A, Chan KL, Mesana TG, Burwash IG. Prosthesispatient mismatch after aortic valve replacement predominantly affects patients with preexisting left ventricular dysfunction: effect on survival, freedom from heart failure, and left ventricular mass regression. J Thorac Cardiovasc Surg. 2006;131:1036-44.

23. Pibarot P, Dumesnil JG. Valve prosthesis-patient mismatch, 1978 to 2011: from original concept to compelling evidence. J Am Coll Cardiol. 2012;60:1136-9. 